\title{
ASSOCIATION OF GASTROESOPHAGEAL REFLUX SYMPTOMS (FREQUENCY AND SEVERITY) WITH BODY MASS INDEX IN FEMALES WITH GASTROESOPHAGEAL REFLUX DISEASE
}

Arshad Rabbani ${ }^{a}$, Benish Adil ${ }^{b}$, Ramsha Ghazal Arshad ${ }^{c}$

${ }^{a}$ Assistant Professor, Department of Medicine Unit-II Benazir Bhutto Hospital, Rawalpindi.

${ }^{\mathrm{b}}$ Post Graduate Resident, Department of Medicine Unit-II Benazir Bhutto Hospital, Rawalpindi.

'House Officer, Medicine Unit-II Holy Family Hospital, Rawalpindi.

\begin{abstract}
:
BACKGROUND \& OBJECTIVE: Overweight individuals have a greater tendency to develop gastroesophageal reflux disease (GERD). This study aims at comparing gastroesophageal reflux symptoms (frequency and severity) in females with different body mass index (BMI) categories.

METHODOLOGY: This cross-sectional comparative research study was conducted over duration of 8 months. Both indoor and outdoor patients of medical unit - II Benazir Bhutto Hospital, Rawalpindi, fulfilling the inclusion criteria i.e. females 30-55 years of age with confirmed diagnosis of GERD and informed consent were included. Subjects with history of cigarette smoking, diabetes, use of postmenopausal hormone replacement therapy (HRT), anti-hypertensive or asthma medication were all excluded. Data were collected via proforma and analyzed on SPSS version 17. RESULTS: Among 360 enrolled women, 08 (2.2\%) subjects were underweight, $109(30.3 \%)$ had normal BMI, 151 (41.9\%) were overweight, 88 (24.4\%) subjects were obese and $04(1.1 \%)$ belonged to morbidly obese group. Among 109 subjects with normal BMI, 53 (48.6\%) had mild, 40 $(36.69 \%)$ moderate, $13(11.9 \%)$ severe and $03(2.75 \%)$ very severe GERD. Among 151 overweight subjects, $37(24.50 \%)$ were with mild severity, $64(42.38 \%)$ with moderate, 35 $(23.17 \%)$ severe and $15(9.93 \%)$ had very severe GERD. Among 04 morbidly obese subjects, 02 $(50 \%)$ had severe while remaining $02(50 \%)$ had very severe GERD $(p=0.000)$.

CONCLUSION: Association of GERD symptoms and BMI were found in both normal and overweight women. Reflux symptoms may be exacerbated or even caused by moderate weight gain in people with normal weight.

KEYWORDS: Body Mass Index (BMI), Gastroesophageal Reflux Disease (GERD), Obesity.

How to cite this:

doi: https://doi.org/10.37723/jumdc.v11i3.428

Rabbani A, Adil B, Arshad RG. ASSOCIATION OF GASTROESOPHAGEAL REFLUX SYMPTOMS (FREQUENCY AND SEVERITY) WITH BODY MASS INDEX IN FEMALES WITH GASTROESOPHAGEAL REFLUX DISEASE. jumdc. 2020;11(3):9-16.
\end{abstract}

doi: https://doi.org/10.37723/jumdc.v11i3.428

This is an Open Access article distributed under the terms of the Creative Commons Attribution License (http://creativecommons.org/licenses/by/4.0), which permits unrestricted use, distribution, and reproduction in any medium, provided the original work is properly cited. 


\section{INTRODUCTION:}

Gastroesophageal reflux disease (GERD) with the characteristic features of acid regurgitation and heartburn is a prevalent disease involving up to $60 \%$ of population at some time during the course of a year and $20-30 \%$ of population at least weekly ${ }^{[1,2]}$. It is among the most common disease of gastrointestinal tract. An incompetent barrier at the gastroesophageal junction leads to backflow of gastric acid and other gastric content into esophagus and that produces symptoms. GERD leads to different complications including reflux esophagitis, peptic stricture and intestinal metaplasia (Barrett's esophagus) which predisposes to adenocarcinoma. In patients with persistent symptoms or complications or those who show no response to therapy, diagnostic studies are required ${ }^{[2,3]}$. Mucosal damage is documented by using barium swallow, esophagoscopy and mucosal biopsy. Quantification of reflux can be done by ambulatory long term (24 hours) esophageal $\mathrm{pH}$ recording.

BMI is the most widely used tool to gauge obesity, which is equal to weight in $\mathrm{kg} /$ height in $\mathrm{m}^{2}\left(\mathrm{~kg} / \mathrm{m}^{2}\right)^{[4]}$. At a similar BMI, women have more body fat than men. BMI of 30 is most commonly used as a cut-off value for obesity in both men and women ${ }^{[5]}$. Some authorities use the term overweight to describe the individuals with BMI between 25 and 30. High BMI is associated with symptoms of GERD in both normal weight and overweight women. Even moderate weight gain among persons of normal weight previously may cause or exacerbate symptoms of gastroesophageal reflux ${ }^{[6,7]}$. Obesity is a risk factor for symptoms of GERD ${ }^{[8]}$. Essential part of treatment of gastroesophageal disease includes weight loss which results in marked improvement in symptoms of GERD. Several cross sectional studies and one metaanalysis conducted in west have depicted a positive association between elevated BMI and symptoms of GERD ${ }^{[8,9]}$. GERD is a lifelong disease that requires life style modification and weight loss ${ }^{[10]}$ besides avoiding acidic foods and products that reduce lower esophageal sphincter tone or delay gastric emptying and reduction of meal size etc. is an important advice to be given to the patients of GERD ${ }^{[11,12]}$. An association between BMI and symptoms of

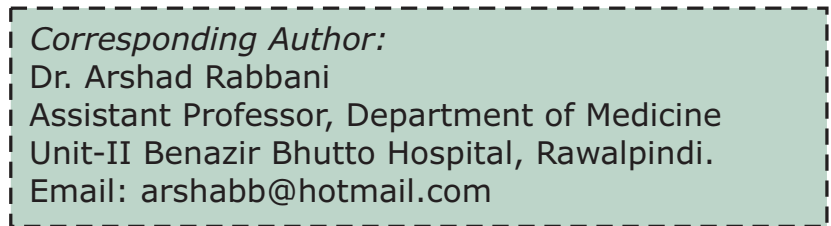

GERD are demonstrated in this study.

The purpose is to determine association between BMI and severity and frequency of symptoms of GERD in Pakistan female population and to make recommendations for patients, health services provider and policy makers.

\section{METHODOLOGY:}

This cross sectional comparative study was carried out on both indoor and outdoor patients of medical unit-II Benazir Bhutto Hospital fulfilling the inclusion criteria. The study was conducted for a period of 8 months, from $17^{\text {th }}$ April 2018 to 17 th December 2018. The study has been approved by the ethical review committee of Benazir Bhutto Hospital, Rawalpindi. Sample size was calculated to be 360 with formula, $n=Z^{2} \mathrm{pq} / \mathrm{E}^{2}$ keeping $5 \%$ error and a prevalence of $57 \%{ }^{[13]}$. Women with age of 30 to 55 years, with symptomatology suggestive of GERD, encompassing all BMI ranges and giving consent were included in the study. Those females with diabetes and cigarette smoking and use of postmenopausal HRT, antihypertensive or asthma medicines were excluded. Females using less than 5 cups per day of coffee or tea were also excluded. After written informed consent and approval of hospital ethical committee prior to the commencement of study, all ethical issues were addressed at every step of data collection i.e. history taking, physical examination and check list for severity of symptoms. Patients fulfilling the inclusion criteria were selected by purposive sampling. BMI of selected subjects was calculated by measuring height and weight and subsequently subjects were segregated in underweight, normal, overweight, obese and morbidly obese groups according to BMI. Questionnaire was given to participants of the study to look for severity of symptoms of GERD and then compared for comparative cross sectional study.

All gathered data was recorded on SPSS version 
17 after manual cleaning. Descriptive statistics, frequencies and percentages were calculated for the background variables, severity and frequency of symptoms and BMI. Mean \pm SD for numerical data like age. Frequency and percentage were applied for gender, social status and BMI. Chi square test was applied to see the difference in proportion of two groups.

\section{RESULTS:}

In this study a total of 360 women were enrolled. Mean age and standard deviation of these subjects was $41.61 \pm 7.69$ years ranging from 30 years to 55 years (Graph-I). BMI of these 360 subjects was calculated by dividing their weight in kilograms with height in meters square. BMI of $8(2.2 \%)$ subjects was below 18.5, belonging to underweight group. BMI of $109(30.3 \%)$ subjects was normal (18.5-24.9), while $151(41.9 \%)$ belonged to overweight group as their BMI ranged between 25 and 29.9. BMI of 88 subjects $(24.4 \%)$ subjects ranged between 30 and 39.9 and they were classified as obese, while $04(1.1 \%)$ subjects belonged to morbidly obese group as their BMI was $>40$ (Table-I).

Among these 360 women, 110 (30.6\%) subjects had mild severity of GERD symptoms. While $141(39.2 \%)$ presented with moderately severe GERD. $81(22.5 \%)$ subjects had severe GERD while 28 ( $7.8 \%)$ belonged to very severe category of GERD (Table-II).Out of total subjects, $02(0.6 \%)$ subjectshad no symptoms of both acid regurgitation and heart burns while $81(22.5 \%)$ had both symptoms with less than a month frequency. Heartburn and acid regurgitation frequency was once a month in 45 $(12.5 \%)$ subjects while $131(36.4 \%)$ had frequency of once a week. $72(20 \%)$ had both symptoms more than once a week and 29

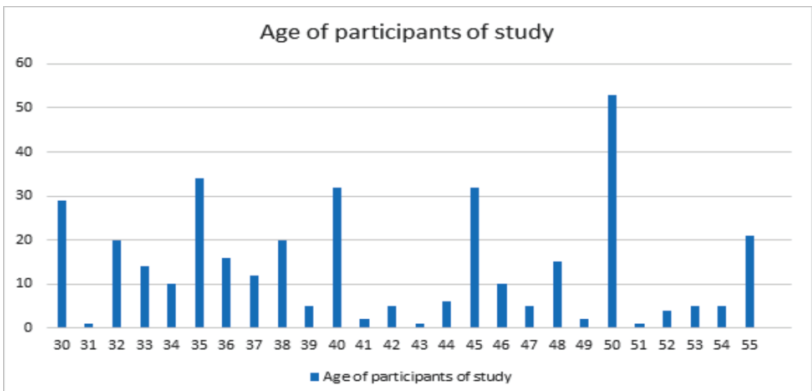

Figure-I: Age of participants of study.
$(8.1 \%)$ subjects had more frequent symptoms of both heart burn and acid regurgitation (Table-III; Graph-II).

All 08 underweight subjects had mild severity while among 109 subjects with normal BMI, 53 $(48.6 \%)$ had mild, 40 (36.69\%) moderate, 13 $(11.9 \%)$ severe and $03(2.75 \%)$ very severe GERD. Among 151 overweight subjects 37 $(24.50 \%)$ were with mild severity, $64(42.38 \%)$ with moderate, $35(23.17 \%)$ severe and 15 $(9.93 \%)$ had very severe GERD. $12(13.6 \%)$ subjects presented with mild severity, 37 $(42.04 \%)$ with moderate, 31 (35.2\%) with severe and $08(9.09 \%)$ presented with very severe GERD among 88 obese subjects. Among 04 morbidly obese, $02(50 \%)$ had severe while remaining $02(50 \%)$ had very severe GERD $(p=0.000)$ (Table -IV). Among 08 underweight subjects, frequency of heart burn and acid regurgitation was as following. $02(25 \%)$ had no symptoms, $04(50 \%)$ less than a month and 02 $(25 \%)$ had these symptoms once a month. Among 109 subjects with normal BMI, 38 $(34.86 \%)$ less than a month, $30(27.52 \%)$ once a month, $28(25.68 \%)$ once a week and 04 $(3.66 \%)$ subjects had more frequent symptoms of heartburn and acid regurgitation.

$27(17.88 \%)$ subjects had a frequency of these symptoms less than a month, $12(7.94 \%)$ once a month, 65 (43.04\%) once a week, 32 $(21.19 \%)$ more than once a week and 15 $(9.93 \%)$ had more frequent symptoms, among 151 overweight subjects. Among 88 obese subjects, $12(13.6 \%)$ had symptoms less than once a month, $01(1.13 \%)$ once a month, 38 $(43.18 \%)$ once a week, 29 (32.95\%) more than once a week and $08(9.09 \%)$ subjects had symptoms more frequently. $02(50 \%)$ subjects had symptoms more than once a week and 02 $(50 \%)$ had more frequent symptoms among 04 morbidly obese subjects $(p=0.000)($ Table-V).

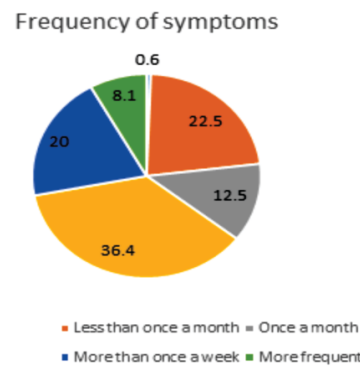

Graph-II: Frequency of symptoms. 
Table-I: Body mass index of participants of study.

\begin{tabular}{|c|c|c|}
\hline & Frequency & Percent \\
\hline Underweight & 8 & 2.2 \\
\hline Normal & 109 & 30.3 \\
\hline Overweight & 151 & 41.9 \\
\hline Obese & 88 & 24.4 \\
\hline Morbidly obese & 4 & 1.1 \\
\hline Total & 360 & 100.0 \\
\hline
\end{tabular}

Table-II: Severity of symptoms in participants.

\begin{tabular}{|c|c|c|}
\hline & Frequency & Percent \\
\hline Mild & 110 & 30.6 \\
\hline Moderate & 141 & 39.2 \\
\hline Severe & 81 & 22.5 \\
\hline Very severe & 28 & 7.8 \\
\hline Total & 360 & 100.0 \\
\hline
\end{tabular}

Table-III: Frequency of Acid regurgitation and heartburn.

\begin{tabular}{|c|c|c|}
\hline & Frequency & Percent \\
\hline None & 2 & 0.6 \\
\hline Less than once a month & 81 & 22.5 \\
\hline Once a month & 45 & 12.5 \\
\hline Once a week & 131 & 36.4 \\
\hline More than once a week & 72 & 20.0 \\
\hline More frequent & 29 & 8.1 \\
\hline Total & 360 & 100.0 \\
\hline
\end{tabular}

Table-IV: Body mass index of participants of study and severity of symptoms.

\begin{tabular}{|c|c|c|c|c|c|}
\hline \multirow{2}{*}{$\begin{array}{c}\text { BMI of participants of } \\
\text { study }\end{array}$} & \multicolumn{2}{|c|}{ Severity of symptoms in participants } & \multirow{2}{*}{ Total } \\
\cline { 2 - 5 } & Mild & Moderate & Severe & $\begin{array}{c}\text { Very } \\
\text { Severe }\end{array}$ & \\
\hline Underweight & 8 & 0 & 0 & 0 & 8 \\
\hline Normal & 53 & 40 & 13 & 3 & 109 \\
\hline Overweight & 37 & 64 & 35 & 15 & 151 \\
\hline Obese & 12 & 37 & 31 & 8 & 88 \\
\hline Morbidly obese & 0 & 0 & 2 & 2 & 4 \\
\hline Total & 110 & 141 & 81 & 28 & 360 \\
\hline
\end{tabular}
$\mathrm{p}=0.000 ; \mathrm{df}=12$

Table-V: Body mass index of participants of study and acid regurgitation and heartburn.

\begin{tabular}{|c|c|c|c|c|c|c|c|}
\hline \multirow[b]{2}{*}{$\begin{array}{c}\text { BMI of } \\
\text { participants of } \\
\text { study }\end{array}$} & \multicolumn{6}{|c|}{ Acid Regurgitation and heartburn } & \multirow[b]{2}{*}{ Total } \\
\hline & None & $\begin{array}{l}\text { Less } \\
\text { than } \\
\text { once a } \\
\text { month }\end{array}$ & $\begin{array}{l}\text { Once a } \\
\text { month }\end{array}$ & $\begin{array}{c}\text { Once } \\
\text { a } \\
\text { week }\end{array}$ & $\begin{array}{c}\text { More } \\
\text { than } \\
\text { once a } \\
\text { week }\end{array}$ & $\begin{array}{c}\text { More } \\
\text { frequent }\end{array}$ & \\
\hline Underweight & 2 & 4 & 2 & 0 & 0 & 0 & 8 \\
\hline Normal & 0 & 38 & 30 & 28 & 9 & 4 & 109 \\
\hline Overweight & 0 & 27 & 12 & 65 & 32 & 15 & 151 \\
\hline Obese & 0 & 12 & 1 & 38 & 29 & 8 & 88 \\
\hline Morbidly obese & 0 & 0 & 0 & 0 & 2 & 2 & 4 \\
\hline Total & 2 & 81 & 45 & 131 & 72 & 29 & 360 \\
\hline
\end{tabular}

$p=0.000 ; \mathrm{df}=20$ 


\section{DISCUSSION:}

Obesity is one of the most prevalent disorders in clinical practice and also most frustrating and challenging to treat ${ }^{[14]}$. Obesity is more quantitatively evaluated by calculating BMI. It is estimated by dividing body weight in kilograms by height in meters square ${ }^{[15]}$. According to National Institute of Health, BMI is defined as normal when it ranges from 18.5 to 24.9, overweight when BMI is from 25 to 29.9. Class I obesity is $30-34.9$, class II obesity when BMI is 35-39.9 and class III or morbid obesity when BMI is $>40$.

Increase in BMI is associated with considerable rise in both mortality and morbidity. Frequency of many diseases increase with obesity. Most common and important of these include hypertension, hyperlipidemia, coronary heart disease and type 2 diabetes mellitus, psychosocial disability, respiratory problems, degenerative joint diseases and depression ${ }^{[16]}$. Obese patients have more surgical and obstetric complications. They have more chances of pulmonary function deterioration, endocrine abnormalities, proteinuria and polycythemia ${ }^{[17]}$. They have greater incidence of central nervous system disorders like stroke due to hyper viscosity, hyperlipidemia and impaired glucose tolerance ${ }^{[18]}$. In middle age and young population, mortality from cardiovascular disorders and mortality from all causes rise in proportion to the degree of obesity ${ }^{[19]}$. Successful treatment of obesity requires a multifaceted approach to behavior modification to change eating habits, to weight loss with hypocaloric diet, aerobic exercise and social support ${ }^{[20]}$.

GERD influences $20 \%$ of adult population, who reports at least once a week episode of heartburn and up to $10 \%$ complain of daily symptoms ${ }^{[21]}$. Mechanism of GERD includes incompetent lower esophageal sphincter resulting in regurgitation of stomach contents into esophagus during swallowing ${ }^{[22]}$. Hiatal hernias are more common in victims of GERD. Reduced peristaltic clearance was found to be present in one third of those suffering from severe GERD ${ }^{[23]}$. Partial gastric outlet obstruction or impaired gastric emptying due to gastric paresis also contributes to and potentiates GERD.
BMI has strong associations with frequency and severity of symptoms of GERD ${ }^{[24]}$. Obesity significantly increases the risk of symptoms of GERD, Barrett's esophagus, erosive esophagitis and esophageal adenocarcinoma. The relationship of GERD with obesity has been confirmed in studies of severe gastroesophageal reflux symptoms and esophagitis related hospitalization ${ }^{[25]}$. In a study conducted by El-serag and colleagues showed increased association of obesity with severity of GERD ${ }^{[26]}$ and the same fact is also highlighted in the results of our study. Our study showed that in underweight subjects, the severity was mild while symptoms were also mild. However, in normal and overweight subjects, more subjects had moderate to severe symptoms resulting in moderate to severe GERD in these categories. The severity of GERD and frequency of its symptoms became severe and more severe in obese and morbidly obese subjects

In another study, overweight subjects greatly increases the chances of having heartburn and acid regurgitation and obese population is almost three times as likely to have symptoms as those of ideal weight ${ }^{[27]}$ and our study results second this fact, as 16 out of 109 participants with normal BMI had severe and very severe symptoms, which makes around $14.6 \%$; while 39 out of 88 participants who were obese had severe and very severe symptoms, which makes around $44.3 \%$. Also 4 out of 4 , i.e. $100 \%$ participants who were morbidly obese had severe and very severe symptoms of GERD.

Another study showed marked association of BMI with symptoms of GERD in both normal and overweight women. It suggested that even among normal weight individuals, risk of symptomatic GERD rises progressively with increasing BMI. Notably weight loss was associated with a reduced chance of symptoms ${ }^{[28]}$. However, this fact could not be compared with our study results as ours was a crosssectional one and the participants enrolled were not followed prospectively for association of weight changes with symptomatology of GERD.

\section{CONCLUSION:}

We conclude that there is strong association between symptoms of gastroesophageal reflux disease and BMI in women. Reflux symptoms 
may be exacerbated or even caused by moderate weight gain among people with normal weight. Managing obesity results in improvement of severity and symptoms of GERD, which is a growing problem worldwide. The study results support that a potential therapy for GERD lies in the evaluation of weight reduction.

ACKNOWLEDGMENT: None

CONFLICT OF INTEREST: All authors disclose no conflict of interest.

GRANT S UPPORT\& FINANCIAL DISCLOSURES: None.

\section{REFERENCES:}

1. Vaezi MF, Katzka D, Zerbib F. Extraesophageal Symptoms and Diseases Attributed to GERD: Where is the Pendulum Swinging Now? Clinical Gastroenterology and Hepatology. 2018;16(7):1018-1029. DOI: $10.1016 /$ j.cgh.2018.02.001

2. Katz PO, Gerson LB, Vela MF. Guidelines for the diagnosis and management of gastroesophageal reflux disease. American Journal of Gastroenterology. 2013; 108(3): 308:328. DOI: 10.1038/ajg.2012.444

3. Martinucci I, Natilli M, Lorenzoni V, Pappalardo L, Monreale A, Turchetti G, et al. Gastroesophageal reflux symptoms among Italian university students: epidemiology and dietary correlates using automatically recorded transactions. BioMed (BMC) Gastroenterology. 2018;18(1):116. DOI: 10.1186/s12876-018-0832-9

4. Bouchoucha M, Fysekidis M, Julia C, Airinei G, Catheline JM, Cohen R, et al. Body mass index association with functional gastrointestinal disorders: differences between genders. Results from a study in a tertiary center. Journal of gastroenterology. 2016;51(4):337-45. DOI: 10.1007/ s00535-015-1111-y

5. Kariri AM, Darraj MA, Wassly A, Arishi HA, Lughbi $M$, Kariri $A$, et al. prevalence and risk factors of gastroesophageal reflux disease in Southwestern Saudi Arabia. Cureus. 2020;12(1): e6626. DOI:10.7759/cureus. 6626. PMID: 31966942

6. Zalar A, Haddouche B, Antonietti $M$, Alhameedi R, Iwanicki-Caron I, Lecleire S, et al. Lack of correlation between morbid obesity and severe gastroesophageal reflux disease in candidates for bariatric surgery: results of a large prospective study. Obesity surgery. 2013;23(11):1939-1941. DOI: 10.1007/s11695-013-1064-2

7. Djärv $T$, Wikman $A$, Nordenstedt $H$, Johar $A$, Lagergren J, Lagergren P. Physical activity, obesity and gastroesophageal reflux disease in the general population. World Journal of Gastroenterology. 2012;18(28):3710-3714. DOI:10.3748/ wjg.v18.i28.3710 PMID: 22851863

8. Hampel H, Abraham NS, El-Serag HB. Metaanalysis obesity and the risk for gastroesophageal reflux disease and its complications. Annals of internal Medicine 2005;143 (3):199-211. DOI:10.7326/ 0003-4819-143-3-200508020-00006

9. Bor S, Lazebnik LB, Kitapcioglu G, Manannikof I, Vasiliev Y. Prevalence of gastroesophageal reflux disease in Moscow. Disease of the Esophagus. 2016;29(2):159-165. DOI:10.1111/ dote. 12310

10. Gong Y, Zeng Q, Yan Y, Han C, Zheng Y. Association between Lifestyle and Gastroesophageal Reflux Disease Questionnaire Scores: A Cross-Sectional Study of 37442 Chinese Adults. Gastroenterology Research and Practice. 2019:5753813. DOI:10.1155/2019/ 5753813.

11. Yadegarfar G, Momenyan S, Khoobi $M$, Salami S, Sheikhhaeri A, Farahabadil M, et al. Iranian lifestyle factors affecting reflux disease among healthy people in Qom. Electron Physician. 2018;10(4): 6718-6724. DOI:10.19082/6718 PMID: 29881536 
12. Spantideas N, Drosou E, Bougea A, Assimakopoulos D. Gastroesophageal reflux disease symptoms in the Greek general population: prevalence and risk factors. Clinical and Experimental Gastroenterology. 2016;9:143-149. DOI: 10.2147/CEG.S103485

13. Kempainen RR, Savik K, Whelan TP, Dunitz JM, Herrington CS, Billings JL. High prevalence of proximal and distal gastroesophageal reflux disease in advanced COPD. Chest. 2007;131(6): 1666-1671. DOI: 10.1378/chest.06-2264

14. Ahmed S, Jamil S, Shaikh H, Abbasi M. Effects of Life style factors on the symptoms of gastro esophageal reflux disease: A cross sectional study in a Pakistani population. Pakistan Journal of Medical Sciences. 2020;36(2):115-120. DOI:10.12669/pjms.36.2.1371

15. Jawed S, Zia S, Tariq S. Frequency of different blood groups and its association with BMI and blood pressure among the female medical students of Faisalabad. Journal of Pakistan Medical Association. 2017; 67(8): 1132-1137.

16. Eslami O, Shahraki M, Bahari A, Shahraki T. Dietary habits and obesity indices in patients with gastro-esophageal reflux disease: a comparative cross-sectional study. BMC Gastroenterology. 2017;17(1):132. DOI:10.1186/s12876017-0699-1

17. Elegal KM, Carroll MD, Ogden $C L$, Jhonson $\mathrm{CL}$. Prevalence and trends in obesity among US adults, 1999-2000. Journal of American Medical Association. 2002; 288: 17231727. DOI: $10.1001 /$ jama.288.14.1723

18. Amin K, Anjum A. Frequency of impaired glucose tolerance in different grades of obesity. Journal of University Medical and Dental College. 2010;1(2):4-7.

19. Yamamichi N, Mochizuki S, AsadaHirayama I, Mikami-Matsuda R, Shimamoto $T$, Konno-Shimizu $M$, et al. Lifestyle factors affecting gastroesophageal reflux disease symptoms: a cross-sectional study of healthy 19864 adults using FSSG scores. BMC medicine. 2012;10(1):45. DOI: 10.1186/1741-7015-10-45

20. Mone I, Kraja B, Bregu A, Duraj V, Sadiku E, Hyska J, et al. Adherence to a predominantly Mediterranean diet decreases the risk of gastroesophageal reflux disease: a cross-sectional study in a South Eastern European population. Diseases of the Esophagus. 2016;29(7): 794-800. DOI: 10.1111 /dote. 12384

21. Bilal N, Akbar N, Khan AB. Obesity is a gateway to complications. Annals of Pakistan Institute of Medical Sciences. 2005; $1: 230-233$

22. Zafar S, Haq I, Butt AR, Shafiq F, Mirza HG, Rehman A. Correlation of Endoscopic severity of Gastroesophageal Reflux Disease (GERD) with body mass index (BMI). Journal of College of Physicians and Surgeon Pakistan. 2007;17:72-75. DOI: 02.2007/jcpsp.7275 PMID: 17288850

23. Nilsson $M$, Johnsen $R, Y e ~ W$, Hveem $K$, Lagergren J. Obesity and estrogen as risk factors for gastroesophageal reflux symptoms. Journal of American Medical Association. 2003;290(1):66-72. DOI:10.1001/jama.290.1.66

24. Vaishnav B, Bamanikar A, Maske P, Reddy A, Dasgupta S. Gastroesophageal reflux disease and its association with body mass index: clinical and endoscopic study. Journal of clinical and diagnostic research. 2017;11(4):OC01-OC04. DOI:10.7860/ JCDR/2017/24151.9562.

25. Richter JE, Rubenstein JH. Presentation and Epidemiology of Gastroesophageal Reflux Disease. Gastroenterology. 2018;154(2):267-276. DOI: 10.1053/ j.gastro.2017.07.045.

26. El-serag HB, Peterson NJ, Carter J. Gastroesophageal reflux among different racial groups in the United States. Gastroenterology. 2004;(7):1692-1699.

27. Aslam M, Slaughter JC, Goutte M, Garrett CG, Hagaman D, Vaezi MF. Nonlinear 
relationship between body mass index and esophageal acid exposure in the extraesophageal manifestations of reflux. Clinical Gastroenterology and Hepatology. 2012;10(8):874-878. DOI:10.1016/ j.cgh.2011.12.032

28. Murray L, Johnston B, Lane A, Harvey I, Donovan J, Nair $\mathrm{P}$, et al. Relationship between body mass and gastrooesophageal reflux symptoms: The Bristol Helicobacter Project. International Journal of Epidemiology. 2003;32(4):645-650. DOI: $10.1093 / \mathrm{ije} /$ dyg 108

\section{Authors' Contribution:}

Arshad Rabbani: Conception and design of study, review and critical analysis of study.

Benish Adil: Design of study, acquisition of data, analysis and interpretation of data.

Ramsha Ghazal Arshad: Acquisition of data and its analysis.

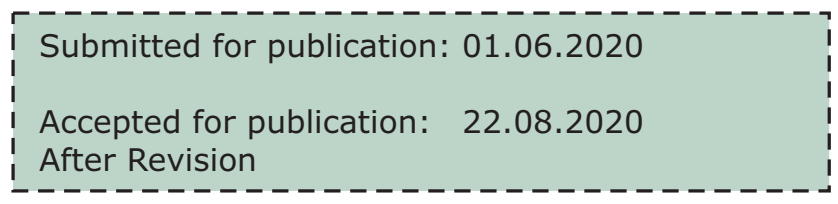

